\title{
Can Energy Trading be a Solution for Indonesia's Energy Mix Goal through Solar Energy?
}

\author{
Zagy Y. Berian ${ }^{1 *}$, Vincent O. Kaulika ${ }^{2}$ \\ ${ }^{1}$ Faculty of Mechanical and Aerospace Engineering, Institut Teknologi Bandung \\ Jalan Ganesha No. 10, Bandung 40132, Indonesia \\ ${ }^{2}$ School of Electrical Engineering and Informatics, Institut Teknologi Bandung \\ Jalan Ganesha No. 10, Bandung 40132, Indonesia
}

Received 30 June 2020; Accepted 12 August 2020

Available online 31 August 2020

\begin{abstract}
Climate change has gotten more and more serious worldwide. To secure the future for our next generation, we need to change the way we use and consume energy from a cleaner source. In Indonesia, this effort is shown through Presidential Regulation No. 22/2017, or general planning of national energy (RUEN) indicates that Indonesia's government is targeting $23 \%$ of energy mix via solar power. However, today, through various industries and consumers level adoption, it is still hard to achieve. The consumer study by Institute for Essential Services Reform (IESR) found that the main issues for the adoption in Jabodetabek are due to lack of consumer incentive, lack of clear benefits of electricity reduction, and poor education about how to install solar power on the consumer level. Throughout this paper, the authors are going to propose a way for energy trading to solve such issues from a top-down perspective. It will start from how the current condition at the consumer level is, the potential scenario, stakeholder benefits analysis, potential location case study, to the commercialization through economic analysis. To achieve the goal of incentivizing customer yet still creating economic sense for the potential investors, which we use state-owned electricity company (PLN) as an example to provide alternatives to a larger scale power plant investment, we experiment on multiple profit sharing mechanisms and scenarios. By varying the profit-sharing factor, we get that 35\%-65\% profit sharing mechanism gives PLN an acceptable payback period and decent profit margin while can still incentivize the customer. From this study on, we can further study the customer buy-in (incentive level) elasticity in correlation with the variation of profit share that is still profitable for the investor or PLN before deciding on the policy.
\end{abstract}

Keywords: energy trading, rooftop solar PV, renewable energy mix, Serpong

\section{Background}

Indonesia is currently consuming electricity with conventional methods. Fossil resources become primary energy to fulfill Indonesia's energy demand despite climate change issues. According to General Planning of National Energy (RUEN), Indonesia is targeting for up to 23\% renewable energy in the energy mix by 2025. The most significant variable renewable energy growth in Indonesia is solar photovoltaic (PV), wind turbines, and hydropower. In a decade, an increasing number of businesses and industries, banking, communication, entertainment, publishing, and many others, have embraced the potential of modernization, automation, and digitalization, with varying degrees of commercial success (Brown et al., 2019). Increasing integration of distributed energy resources (DERs) leads a change to the new-fashioned energy business that gives a chance to direct energy trading called by peer-to-peer (P2P) and usually enabled by information and communication (ICT) based online services. The main issues for the adoption in Jakarta, Bogor, Tangerang, and Depok (Jabodetabek) are due to lack of consumer incentive, lack of clear benefits of electricity reduction, and poor education about how to install solar power on the consumer level (IESR, 2020). Currently, Indonesia's electricity system is centralized by state-owned electricity company (PLN), meanwhile the other developing countries are

* Corresponding author
E-mail address: zagyyakana@gmail.com 
planning to adopt the decentralized system. It must start the first step before a decentralized system by implementing electricity export-import to PLN with an integrated system. The one million solar PV rooftop program from the government is only beneficial from government and private sector perspective. This paper aims to build Indonesia's first step to achieve the targeted renewable energy mix through energy trading between residential areas and PLN with a new business scheme. PLN will offer the residential areas to install the solar PV rooftop with a good electricity price. The recommendation for the first step is going to be focusing more on the use of the combination of the right policy, incentives, and stakeholders that will produce an operating model proven through a simple financial model by the authors.

\section{Literature Study}

This literature study begins with energy trading to describe the current situation about energy trading in the world. Then, research Indonesia's current electricity system condition such as energy mix target, current strategy, and solar PV condition. Explain model of the sun from previous research to estimate solar energy potential. Last, explain net present value to analyse the profitability of a projected investment.

\subsection{Energy Trading}

The concept of P2P comes from electricity generation of DERs is usually intermittent and difficult to predict. The idea is when they have surplus electricity, they can curtail it, store it with energy storage devices, export it back to the power grid, or sell it to other energy consumers (Zhang et al., 2016). Leading countries such as the United Kingdom, Netherlands, and Germany have developed P2P electricity trading platforms that allow direct trading of electricity between the energy prosumer and consumer.

The concept of P2P electricity trading has become familiar to the public. There have been many studies that analyzed the $\mathrm{P} 2 \mathrm{P}$ electricity trading method using various models such as the auction-based model (Chen et al., 2019; Leong et al., 2019; Tushar et al., 2016), bilateral contract-based model (Morstyn et al., 2019), and decentralized model through blockchain (Mengelkamp et al., 2017). P2P electricity trading can be achieved through the smart grid. A smart grid architecture model (SGAM) framework was proposed by European committee for standardization (CEN), European committee for electrotechnical standardization (CENELEC), and European telecommunications standards institute (ETSI) to enable the European standardization organization to perform continuous standard enhancement and development in the field of SGAM. Another architecture based on the SGAM framework was proposed to implement the P2P business model called by Elecbay (Zhang et al., 2016) and motivated this work to build Indonesia's roadmap indicator.
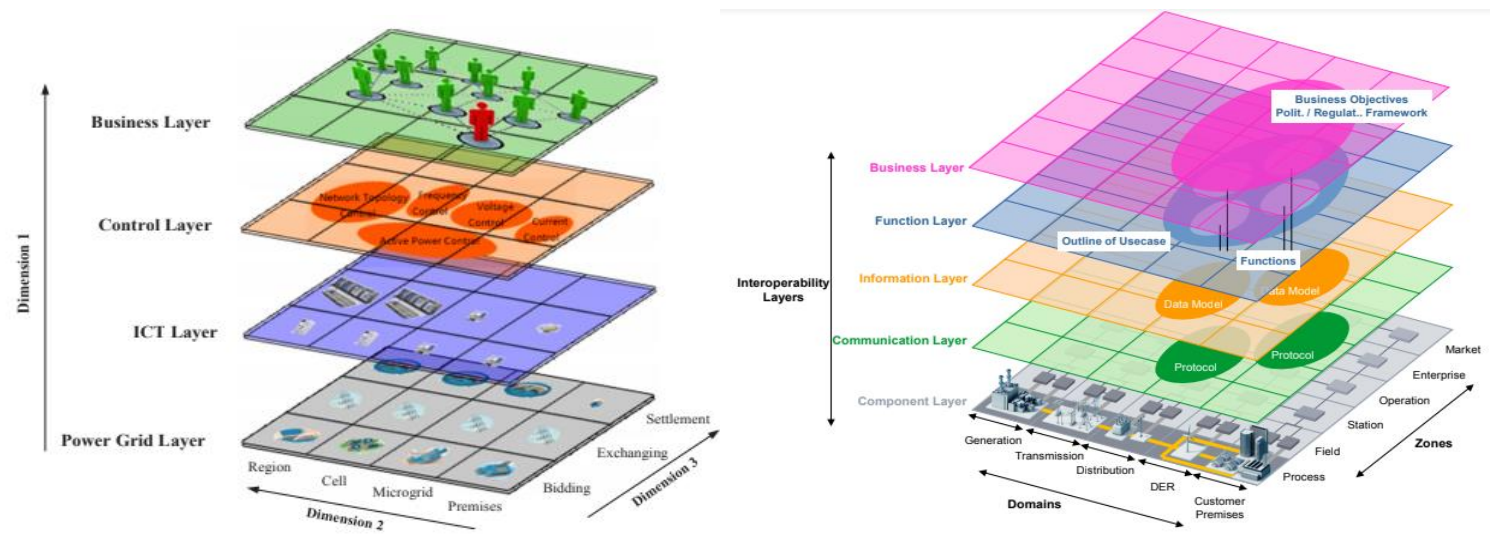

Figure 1. Smart Grid Architecture Model (SGAM) (Zhang et al., 2016). 
There are three dimensions in the system architecture, and the first dimension included four layers that become crucial functions such as power grid, ICT, control layer, and business layer. The second dimension of the system architecture is about the size of the peers participating in P2P energy trading; the dimensions from are premises, microgrids, cells, and regions respectively in order from the smallest to the largest. The third dimension explains the time sequence of the $\mathrm{P} 2 \mathrm{P}$ energy trading process.

In the first dimension, the power grid layer comprises all physical components (e.g., feeders, transformers, smart meters, loads, DERs) where P2P energy trading is. ICT layer consists of communication devices (e.g., sensors, wired/wireless communication connection, routers, switches, server, and computer), protocols (e.g., transmission control protocol (TCP)/ internet protocol (IP), point-to-point (PPP)), applications (e.g., a platform to transfer information and file exchange) and information flow (i.e., flow between senders, receivers, and communication devices). The control layer organized the control function of the electricity distribution system (e.g., voltage control, frequency control, and active power control) to preserve the quality and reliability of power supply and control the power flow. The business layer determines how electricity is traded among peers and with the third parties (e.g., peers, suppliers, distribution system operators (DSOs), and energy market regulators).

The second dimension, individual premise refers to one single house connected to the electricity distribution system. Microgrids usually consist of several premises and DERs in a local geographical area that shares the same medium-voltage (MV)/ low-voltage (LV), which operates in a controlled and coordinated way either on-grid or off-grid. Cells consist of several Microgrids that can operate either on the grid or off the grid. A region can be substantial as a city or metropolitan area which consists of multiple cells. A peer can consist of all components in the second dimension and trade with each other.

The third dimension explains the time sequence of the $\mathrm{P} 2 \mathrm{P}$ trading process. Bidding is the first process of P2P energy trading when energy customers (e.g., generators, consumers, and prosumers) reach trading agreements with each other before the energy exchange. After reaching the agreements, it will go to the energy exchange in which energy is generated, transmitted, and consumed. Finally, when the bills and transactions are finally settled via settlement arrangement and payment, settlement happens.

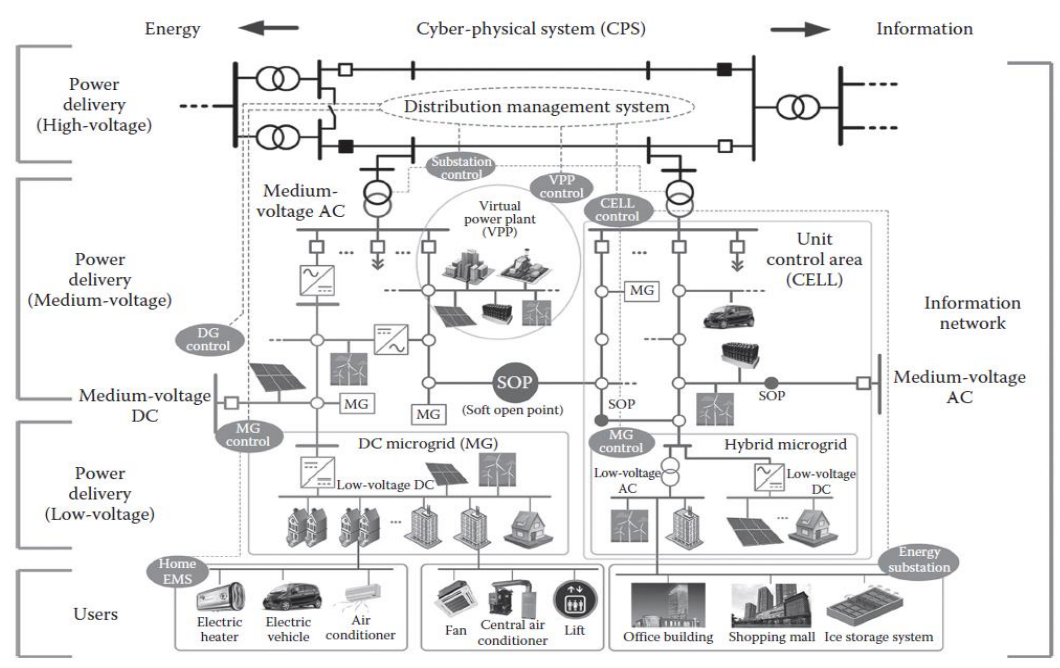

Figure 2. Diagram of a Smart Distribution System (Wang et al., 2017).

Fully decentralized market, in a fully decentralized P2P market, participating prosumers can independently and directly negotiate with one another to decide on the energy trading parameters without any centralized supervision. Such decentralization of a P2P market relies on bilateral contracts between individual prosumers as proposed in (Morstyn et al., 2019). Through the designed contract, captures both upstream-downstream energy balance and forward market uncertainty within the model (Morstyn et al., 2019). The authors propose another fully decentralized market for multi-bilateral economic dispatch, where prosumers with energy demand can choose their preferences for the type of 
energy source, such as local or green energy, for trading. Besides fully decentralized, there are community-based and composite market. A community-based P2P market can readily be applied to community microgrids. Composite market is essentially a combination of fully decentralized and community-based markets in which each community and each single prosumer can interact with one another, while maintaining their own market properties. That is, on the one hand, each individual prosumer can engage in $\mathrm{P} 2 \mathrm{P}$ trading between themselves, while also interacting with existing markets like fully distributed markets (Tushar et al., 2016).

\subsection{Current Condition for Indonesia's Electricity System}

Indonesia's government is planning to develop $56 \mathrm{GW}$ with coal still as a dominant resource in the energy mix. The target for $23 \%$ renewable energy of total energy by 2025 will utilize more hydropower and geothermal. According to IRENA, the cost of solar PV and wind energy are competitive in the present and will still reduce significantly by 2030 (IRENA, 2020). RUEN has been designed in terms of Indonesia's need, then create the roadmap, it needs to consider socio-economic and environment to achieve a more comprehensive roadmap (IRENA, 2020). Indonesia is still prioritizing to fulfill the demand for energy rather than the clean factor of the energy itself; it makes coal more feasible to utilize because it has a price cheaper compared to other alternatives. When we look further, in the next decade, we need to consider alternative energy to achieve sustainability either in energy or climate. Indonesia has a massive potential of renewable energy (RUEN), solar PV and wind energy can be an option to be utilized since the price is going to be more competitive to coal. By November 2019, $152 \mathrm{MW}$ of solar PV had been installed. Although 2019 achieved a higher growth of solar energy (tripled the addition in 2018), with 44\% increment year-on-year it is still far from RUEN target at 550 MW by the end of 2019. The progress in 2019 mainly came from utility-scale solar power plant.

Furthermore, Indonesia has one million rooftop solar PV program (ESDM). A regulation for implement rooftop solar PV stated in Ministerial Regulation No. 49/2018, the regulation stated net mattering calculation. While consumer excess electricity, it must multiply by $0.65(65 \%)$ to calculate the price that owners export to State Electricity Company (PLN). The scheme named by net metering, the result accumulation between export and import electricity, as shown in Figure 3. The number of rooftop solar PV owners significantly increased from 351 in 2017 to 1,435 owners in 2019, estimating for $16.66 \mathrm{MW}$ of total solar PV capacity in 2019 (IESR, 2020).

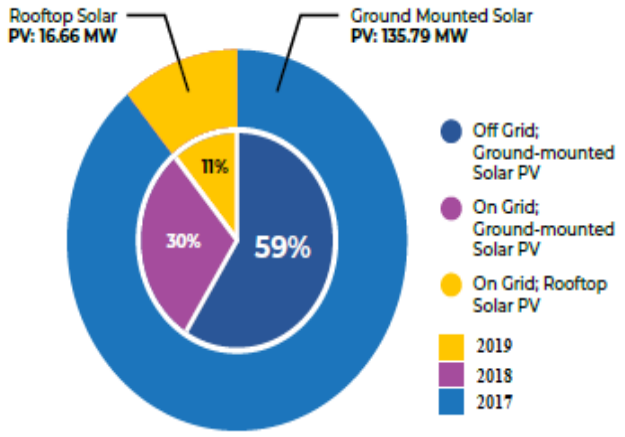

Figure 3. Slow progress of Solar PV development (IESR, 2020).

To adopt the P2P energy trading, it only can implement for the residential that installed solar PV rooftop or other renewable energies thus the residential can be called by prosumer. If the one million rooftop solar PV perform slow progress and the government still does not create pilot project for P2P energy trading, Indonesia will always behind the other countries. Based on smartgrid architecture, Indonesia does not have an ICT layer and the control layer still does not perform well.

\subsection{Consumer Needs Study}

In July-August 2018, The Deutsche Gesellschaft für Internationale Zusammenarbeit (GIZ) surveyed 500 households in Jakarta, Bogor, Depok, Tangerang, and Bekasi (Jabodetabek). Their houses have 
equals to $1,300 \mathrm{VA}$ or more electrical capacity and have the right to decide on electricity use. This survey was then analyzed further by the Institute for Essential Services Reform (IESR). The survey has shown that 7 out of 10 people are interested in rooftop solar PV. Most of the respondents have positive perceptions of rooftop solar PV. Three top reasons were that it is interesting (47 respondents), it saves energy (26 respondents), and it reduces electricity bills (20 respondents). However, only $8 \%$ of the respondents consider that rooftop solar PV is relevant to their needs. Most of the reasons are that they do not know about rooftop solar PV products, they have not seen it by themselves, do not know the price, or do not have the budget. Furthermore, only $13 \%$ of the respondents are willing to buy and install rooftop solar PV, and $85 \%$ of them are willing to buy and install given clear regulation from the government.

IESR have four recommendations, such as the following:

- In order to catalyze rooftop solar PV in Indonesia, governments have to give clear information to a multitude of dimensions (residential, industrial, business, and commercial) about the benefits of rooftop solar PV, technical matters, and funding or incentives; through various media including mass media.

- The government shall introduce a supportive regulation towards the installation of rooftop solar PV in Indonesia, including ease of installation and net-metering services with fair because one of the expected main benefits by the customer is the reduction of electricity bill and a payback period lower than ten years.

- The government shall incentivize customers, such as through tax incentives, and encourage financial services organizations to provide a loan product for rooftop solar PV with a low rate and short tenor.

- The government has to encourage the local rooftop solar PV industry to consider high interest for local products and to ensure the quality through service providers national standard.

\subsection{Model of The Sun}

To estimate solar energy in a specific location, it can estimate by using Parabolic Trough Concentrator (PTC) calculation to collect energy from the sun (Duffie \& Backman, 1980). First, it needs angle of day (Spencer, 1971) (in degrees):

$$
B=\frac{360}{365}(n-1)
$$

Where $n$ is a selected day and $n=1$ is $1^{\text {st }}$ January. Then, it needs an equation of time (Spencer, 1971) defined by the correction time factor (in minutes):

$E=229.2(0.000075+0.001868 \cos B+0.032077 \sin B-0.014615 \cos 2 B-0.04089 \sin 2 B$

Then, it needs to find the reference median ( $\left.\mathrm{L}_{\mathrm{st}}\right)$ (in degrees) in terms of different time with coordinated universal time (UTC) as follows.

$$
L S T M=15^{\circ} \Delta T u t c
$$

Where $\Delta T u t c$ is the differences between local time and UTC.

After the reference median, it needs time correction factor (in minutes). It will be negative for eastern longitude and positive for western longitude.

$$
T C= \pm 4\left(L_{s t}-L_{l o c}\right)
$$

To obtain solar time (hour), the local time has to be corrected by time correction as equation below.

$$
L S T=L T+\frac{T C}{60}
$$

Where the local solar time had found, it needs to convert into hour angle (degree).

$$
\omega=15^{\circ}(L S T-12)
$$


To track the sun, it needs declination angle (degree) (Cooper, 1969) as in the equation below.

$$
\delta=23.45 \sin \left(360 \frac{284+n}{365}\right)
$$

To obtain incident angle at $\mathrm{N}-\mathrm{S}$ alignment as equation below.

$$
\cos \theta=\left(\cos ^{2} \theta_{z}+\cos ^{2} \delta \sin ^{2} \omega\right)^{1 / 2}
$$

Where $\theta_{z}$ can find using equation below.

$$
\cos \theta_{z}=\sin \delta \sin \phi+\cos \delta \cos \phi \cos \omega
$$

To get beam radiation in clear sky models, it needs to calculate the extraterrestrial radiation incident (Spencer, 1971) as follow:

$$
G_{\text {on }}=G_{S c}\left(1+0.033 \cos \frac{360 n}{365}\right)
$$

Previous research has presented a method to estimate the beam radiation transmitted through clear atmospheres (Hottel, 1976). The atmospheric transmittance for beam radiation $(\tau b)$ is given in the form:

$$
\begin{gathered}
\tau_{b}=a_{0}+a 1 \exp \left(-\frac{k}{\cos \theta z}\right) \\
a_{0} *=0.4237-0.00821(6-A)^{2} \\
a_{1} *=0.5055+0.00595(6.5-A)^{2} \\
k *=0.2711+0.01858(2.5-A)^{2}
\end{gathered}
$$

For the tropical climate the following $a_{0} *, a_{1} *, a_{1} * k *$ are $0.95,0.98$, and 1.02

Clear-sky horizontal beam $\left(\mathrm{W} / \mathrm{m}^{2}\right)$ is given by:

$$
G_{c b}=G_{o n} \tau_{b} \cos \theta
$$

It can also estimate the clear- sky diffuse radiation on a horizontal surface to get the total radiation (Liu \& Jordan, 1960). Clear-sky horizontal diffuse $\left(\mathrm{W} / \mathrm{m}^{2}\right)$ is given by:

$$
G_{c d}=G_{o n} \cos \theta\left(0.271-0.294 \times \tau_{b}\right)
$$

To obtain the total radiation $\left(\mathrm{W} / \mathrm{m}^{2}\right)$ using the equation below.

$$
G_{c t}=G_{c b}+G_{c d}
$$

\subsection{Net Present Value}

Net present value (NPV) is the difference between the present value of cash inflows and the present value of cash outflows over some time. NPV is used in capital budgeting and investment planning to analyze the profitability of a projected investment or project.

To calculate NPV, the general formula:

$$
N P V=\sum_{t=1}^{n} \frac{R_{t}}{(1+i)^{t}}
$$

Where $R_{t}, I$, and $t$ are net cash inflow-outflows during a single period $t$, discount rate, and number of timer periods. A positive net present value indicates that the projected earnings generated by a project or investment in present dollars-exceed the anticipated costs, also in present dollars. The assumption is that an investment with a positive NPV will be profitable, and an investment with a negative NPV will 
result in a net loss. This concept is the basis for the NPV Rule, which dictates that only investments with positive NPV values shall be considered.

\section{Methodology}

This research's methodology consists of generating several scenarios to achieve the target using rooftop solar PV and comes up with a suitable scenario. After selecting the appropriate scenario, the authors are going to simulate energy trading from a potential location in Indonesia using empirical formulas and the formulas can be used for specific location. This research will select the potential area based on energy potential, consumer electricity behavior, and geographical opportunity. Then, conduct energy simulation trading to estimate potential electricity that can be verified from the location using the model of the sun (theoretical). The authors will assume the capacity installed in each house. The authors will further estimate daily energy production using the duration of daily sunshine data from Meteorological, Climatological, and Geophysical Agency (BMKG) in 2018. Finally, the authors will present the financial model scenario to test the proposed innovation model.

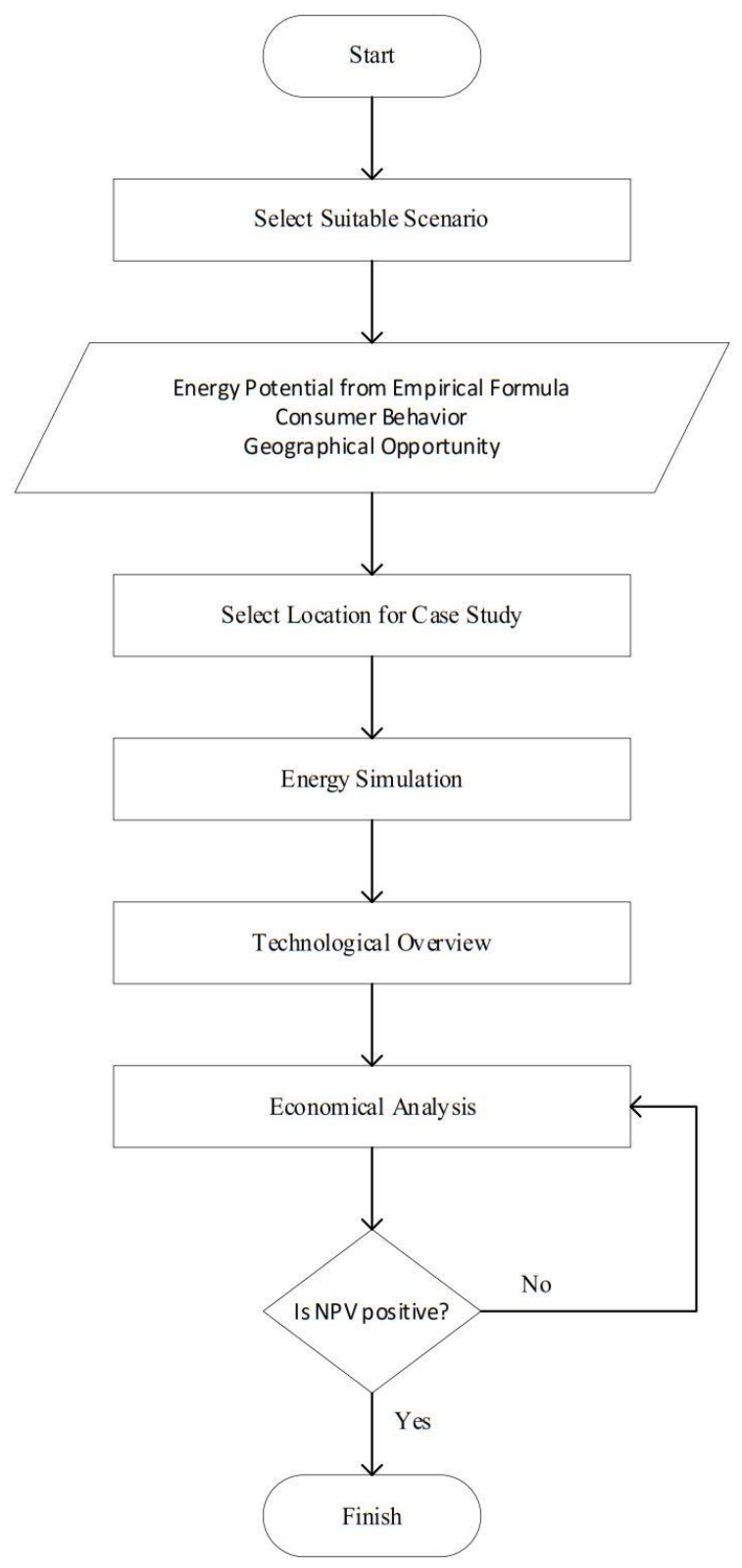

Figure 4. Flow diagram. 


\section{Analysis}

This section is structured based on the methodology, begins with scenarios and finish with the economic analysis.

\subsection{Scenarios}

For Indonesia to achieve that target using rooftop solar PV, there are several scenarios that the authors consider (Table 1), such as the followings:

\subsubsection{Scenario 1 (personal capital through net metering or current scenario)}

In this scenario, the house-owners must learn, procure, install, and maintain all the equipment by themselves. The ways they can get benefits are through electricity bill reduction, and net-metering methodology for exported energies with a multiplication by a margin factor covered by the PLN according to the national policy by the ministry of the energy.

\subsubsection{Scenario 2 (shared initial capital by government through PLN and the consumer)}

In this scenario, the initial investment is split between the house owner and PLN. The profit-sharing scenario is also like that of Scenario No. 1. However, the margin factor might slightly differ and favor PLN more because the payback period concerns now is shared between PLN and the consumer.

\subsubsection{Scenario 3 (initial capital by government through PLN only)}

In this scenario, PLN, entirely covers the initial investment for the rooftop solar PV system for the consumer. All the consumers need to provide for is the consent for the land and asset installation. For the profit-sharing scenario will also be similar to that of Scenario 2. Another way to see this scenario is that the PLN owns a micro-grid, a smaller Solar Power Farm (PLTS), that is installed in each of the consumers' houses. Based on the referred literature study by the IESR, we can see that there are several parameters that we can use to decide the likelihood to reach the renewable energy mix target. The parameters are consumers' incentives, the stakeholders' long- term benefits, and the time needed for educating the consumers before making a purchasing decision.

To pick based on the parameters, the authors try to layout each scenario and see how they compare with one another. 
Table 1. Scenarios Comparison.

\begin{tabular}{|c|c|c|c|}
\hline Scenario & $\begin{array}{r}\text { Consumers' } \\
\text { Incentives } \\
\end{array}$ & Stakeholders' Benefit & $\begin{array}{c}\text { Needed Time for } \\
\text { Education }\end{array}$ \\
\hline S1 & $\begin{array}{l}\text { Lower as the } \\
\text { customers must } \\
\text { invest themselves } \\
\text { while they are still } \\
\text { required by the } \\
\text { regulation to share } \\
\text { the produced } \\
\text { electricity profits } \\
\text { and sell it to PLN at } \\
\text { a lower price. }\end{array}$ & $\begin{array}{l}\text { PLN: Decrease of profitability } \\
\text { but still making a profit as they } \\
\text { do not have to cover the land } \\
\text { and initial investment but still } \\
\text { get margin. } \\
\text { Ministry of Energy: } \\
\text { Renewable mix goal can take a } \\
\text { longer time to take place. } \\
\text { - Consumers: } \\
\text { Lower electricity bills from } \\
\text { self-consumption and excess } \\
\text { energy grid transfer. }\end{array}$ & $\begin{array}{l}\text { Longer as only a tiny } \\
\text { percentage of consumers } \\
(13 \%) \text { want to make that } \\
\text { investment call given } \\
\text { with clear regulation by } \\
\text { the government. }\end{array}$ \\
\hline $\mathrm{S} 2$ & $\begin{array}{l}\text { Moderate as the } \\
\text { customers still must } \\
\text { invest a percentage } \\
\text { amount of money, } \\
\text { albeit a lower } \\
\text { amount compared to } \\
\text { S1, and share more } \\
\text { of their profit to the } \\
\text { government/PLN. }\end{array}$ & $\begin{array}{l}\text { PLN: Slight decrease in } \\
\text { profitability but PLN is still } \\
\text { making a profit as they do not } \\
\text { have to cover the land and } \\
\text { initial investment but still get } \\
\text { margin and be able to sell back } \\
\text { to the household itself. In the } \\
\text { long run, it will be a full profit } \\
\text { for PLN after the payback } \\
\text { period. } \\
\text { Ministry of Energy: } \\
\text { Renewable Mix Goal can take } \\
\text { a moderate time to take place } \\
\text { Consumers: } \\
\text { Lower electricity bills from } \\
\text { self-consumption and excess } \\
\text { energy grid transfer. Lower } \\
\text { investment cost. }\end{array}$ & $\begin{array}{l}\text { Moderate as only a tiny } \\
\text { percentage of consumers } \\
(13 \%) \text { want to make that } \\
\text { investment call given } \\
\text { with clear regulation by } \\
\text { the government, but now } \\
\text { that it is partially } \\
\text { supported and } \\
\text { incentivized through } \\
\text { shared investment } \\
\text { scheme, it will encourage } \\
\text { and catalyze the } \\
\text { installation even more. }\end{array}$ \\
\hline S3 & $\begin{array}{l}\text { High as all } \\
\text { consumers need to } \\
\text { provide is their } \\
\text { rooftop, and they } \\
\text { will enjoy the } \\
\text { benefit of lower } \\
\text { electricity bills. }\end{array}$ & $\begin{array}{l}\text { PLN: Slight decrease in } \\
\text { profitability, but PLN is still } \\
\text { making a profit, and in the long } \\
\text { run, it will be a full profit for } \\
\text { PLN after the payback period. } \\
\text { It is as if PLN owns a micro } \\
\text { solar power grid without } \\
\text { having to invest in land } \\
\text { ownership. However, the } \\
\text { payback period is now in the } \\
\text { PLN's burden. } \\
\text { Ministry of Energy: } \\
\text { Renewable Mix Goal can take } \\
\text { place just in time. } \\
\text { Consumers: } \\
\text { Lower electricity bills from } \\
\text { self-consumption and excess } \\
\text { energy grid transfer and do not } \\
\text { have to pay for investment } \\
\text { cost. }\end{array}$ & $\begin{array}{l}\text { The shortest as it handles } \\
\text { the objection of having } \\
\text { no budget nor education } \\
\text { for the benefits as a } \\
\text { project can be introduced } \\
\text { in a specific targeted } \\
\text { area; therefore, it does } \\
\text { not need to use mass } \\
\text { media to broadcast to an } \\
\text { unspecific number of } \\
\text { consumers. }\end{array}$ \\
\hline
\end{tabular}

From those parameters, we can see that S3 excels compares to the rest of other scenarios. In the background, we also conduct customer benefits and the investment payback period for the stakeholders. 


\subsection{Location Target for Case Study}

Indicators for the location are energy potential, consumer behavior, and geographical opportunity. The more reasons as listed below.

\subsubsection{Energy Potential}

To estimate the energy potential, by using formulations that are described in the previous section. The solar heat flux in this research location (i.e. pre-selected Serpong, South Tangerang) to be a project location as shown in Figure 5. According to irradiance energy estimation from three-sample such as January, July, and December. Figure 5 is showing the result from three-sample and average irradiance energy from 00.00-24.00. It shows that the energy only available from 07.00-17.00 with peak around 12.00. December has the highest energy compared to others while July has the lowest, but the average still indicates good potential in that location.

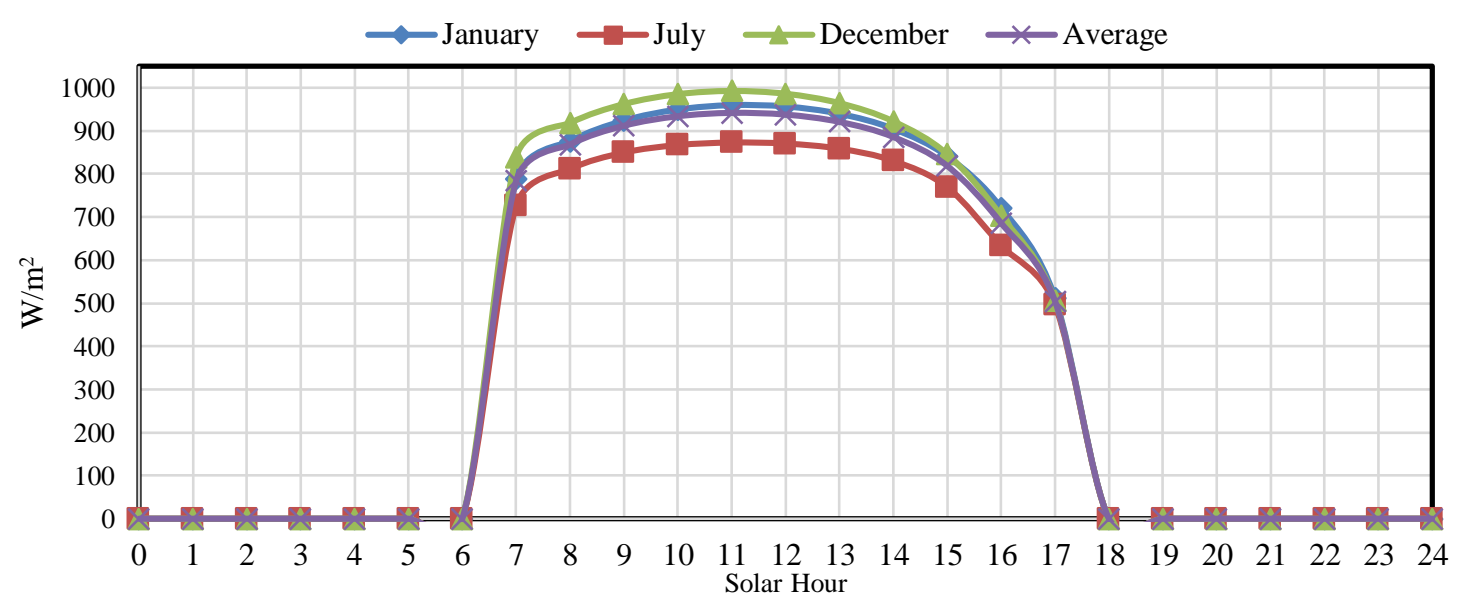

Figure 5. Solar Irradiance Graph in Location Target.

\subsubsection{Geographical Opportunity}

Serpong has a significant growth compared to other areas in Java Island. There are so many business sectors that are available in Serpong. A nearby distance between the business sector and residential give advantage. For example, it could sell excess residential electricity to the business sector while implementing energy trading.

\subsubsection{Consumer Behavior}

According to BPS (2008), a household dominantly categorized by middle up and technologically avid. It could be beneficial to implement rooftop solar PV for energy trading.

\subsection{Energy Simulation}

This simulation assumes 60 houses and sets the amount of rooftop solar PV capacity of each house by 1.5 KWP, 0.85 Power Factor (PF) correction, and 0.7 average excess electricity of install capacity to estimate annual production. It needs a duration of daily sunshine from BMKG to estimate daily energy that could be generated in one day. This simulation case selects Amethyst Residential in Serpong, South Tangerang. 
Table 2. Daily Characteristic of The Sun.

\begin{tabular}{ccccc}
\hline Month & January & July & December & Average \\
\hline Daily sunshine (BMKG's data) & 6 & 4.4 & 6.3 & 5.7 \\
Daily energy production $(\mathrm{kWh})$ & 9.00 & 6.60 & 9.45 & 8.35 \\
Daily net energy $(\mathrm{kWh})$ & 6.30 & 4.62 & 6.62 & 5.85 \\
\hline
\end{tabular}

Annual production can be estimated from average daily energy production. The Amethyst residential can generate annual electricity in the amount of $128.4 \mathrm{GWh}$.

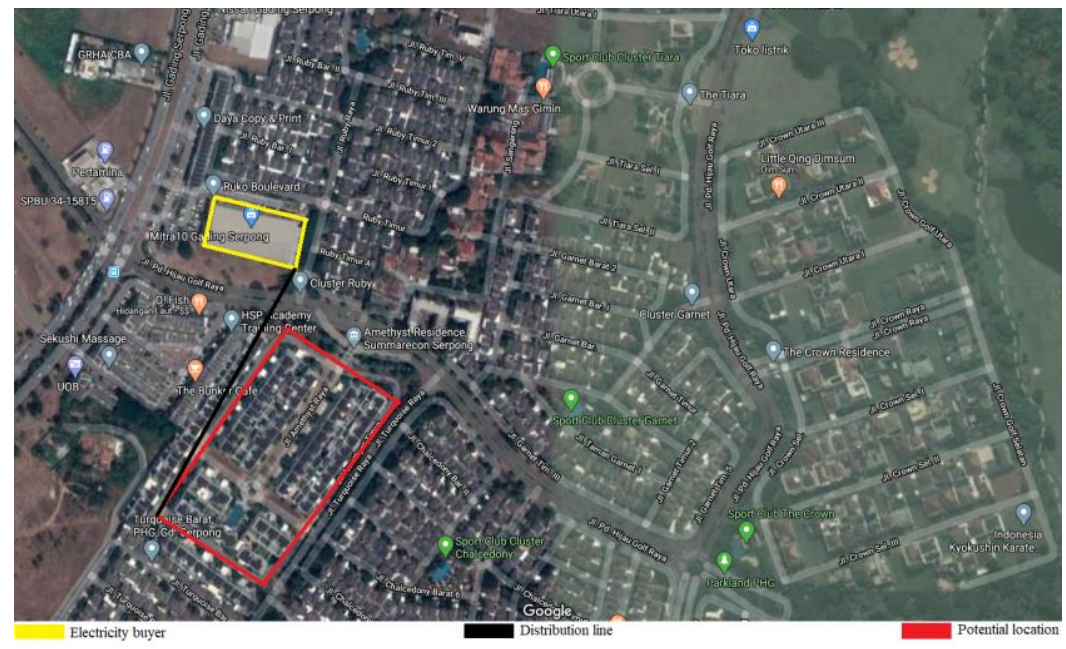

Figure 6. Location Target (Google Maps, 2020).

\subsection{Technological Overview}

Based on the current condition in the literature study, we can see that mainly the technological scenario that is offered by PLN is using the net-metering method. Net-metering is where PLN installs a two-way electrical meter in every consumer. The technology is already widely available in the market. However, the authors have to acknowledge that one of the critical enablers of all the scenarios is that the prosumer can resell to the PLN as the community manager in the community-based market according to (Tushar et al. 2020), who regulates the electricity distribution. This way, the building owner can not only profit from electricity bills reduction but also from selling the excess electricity, making the payback period quicker. In the implementation, however, different buildings might have different energy use profile. If the community manager can oversee and anticipate the energy transfer and energy use from a building to another, it will surely give an advantage to ensure the grid stability by providing the right amount of energy. It will have an even significant impact when the proposed system expands, and another similar microgrid is added to the system. In order to achieve that result, the authors are proposing to add another additional electrical metering system to the center of each microgrid that regulates the electrical power flow.

In the current net-meter system in Indonesia, the export line from the consumer is connected directly to the grid. However, before the line from the line from net-meter reaches the distribution line, PLN can install an electricity meter that will connect through a network communication with the electricity management system (EMS) that regulates the electricity flow. The system will then be able to track the consumption of each prosumer from time to time and plan accordingly. The system can then be integrated with the comprehensive flow analyzer and adjust with a trading algorithm that will enable a fully autonomous trading system. This trading system will then remove the conflict of interest from each stakeholder. 


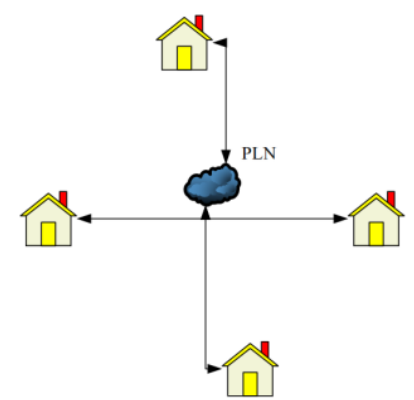

Figure 7. Proposed Technological Alternative.

\subsection{Economical Analysis}

In order to come up with the economic analysis, the authors will first take into account the potential energy generated from a single project in a specific proposed case study location. First, we can already see that the number of the projection for the energy generation in section 4.3. Then, the authors assume a specific margin factor that will be used by the PLN. It is a 35\% - 65\% scheme where whenever they buy the electricity from the household, they will be paying $35 \%$ of the market price, which means $35 \%$ of the export value in the metering system and the PLN will gain $65 \%$ of profit margin for every sold $\mathrm{kWh}$. It is mandatory to incentivize user for the excess electricity they have, to discount their electricity consumption depends on how much electricity they use back on their own. However, the authors found out that for this scheme to be profitable for PLN at current prices, the magic number is $40 \%$ of the regular market price and $60 \%$ profit margin for PLN at the minimum level with a barely positive NPV throughout the product lifetime with the same capitalization \& amortization. The number is relatively low compared to a conventional solar farm system as the PLN does not have to invest in the land-use. However, this number still means that an additional policy should be imposed to offset the change of the proposed scheme.

The authors also then assume the cost of investment for a $1.5 \mathrm{kWp}$ rooftop solar PV system from a vendor in the Indonesia market in a household. Finally, the initial investment is added with the cost of installing the communication system essential to cover the ICT layer for the recommended Peer-to-Peer electricity trading to ensure grid stability.

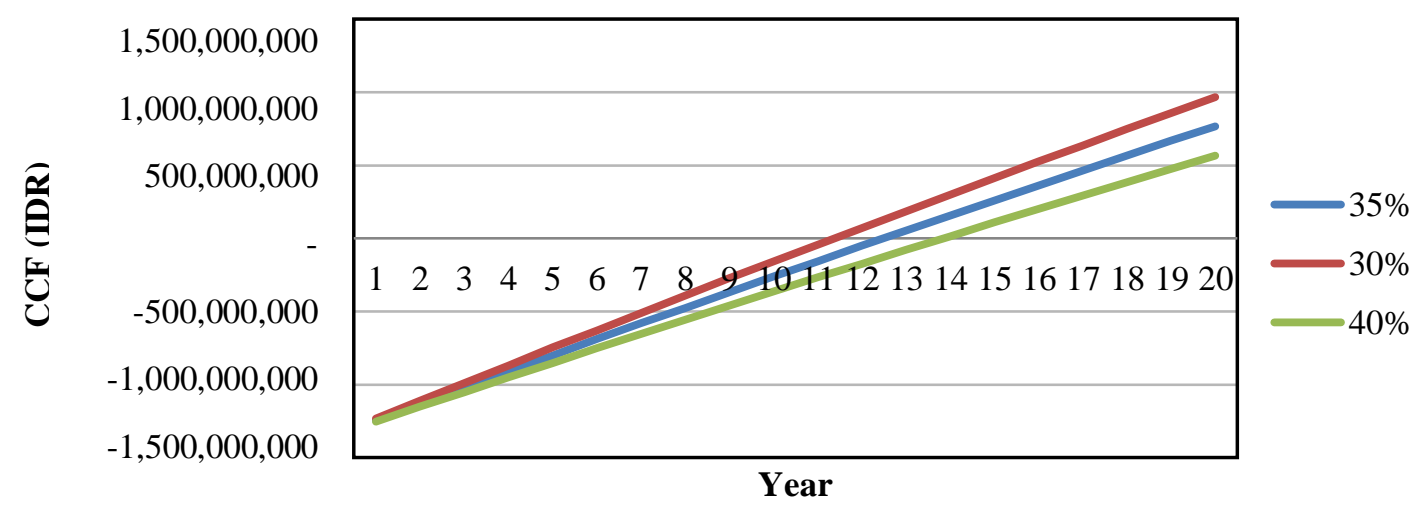

Figure 8. Cumulative Cash Flow.

The amount of initial investment for the system in an area or microgrid is estimated to be around IDR $1,356,500,000.00$. The initial investment will then be capitalized and amortized throughout the expected payback period of a conventional system in a household around 11 years with the current electricity price. Throughout the lifetime of the rooftop solar PV system, we are observing a net positive present value (NPV) by assuming a 5\% discount rate, which means the investment for such a scheme is economically feasible. Meanwhile, Internal Return Rate (IRR) is $14 \%$. 


\section{Conclusion}

From the authors' analysis, we are pursuing a scenario that is highly likely for the Indonesia government to achieve the renewable energy mix target. The scenario requires PLN as a state-owned enterprise to pay upfront cost for the installation for rooftop solar PV in an area and benefit from the solar trading services that it provides. This scheme can give a clear benefit for all the stakeholders from PLN, Government, and the potential Prosumer. Through the simulation in a case study, however, the authors observe that there might be a need for policy adjustment for the current scenario/scheme to be feasible. The additional policy might give PLN/Potential a better advantage to invest in such a scheme. For the long run of the microgrid project expansion, the authors are also proposing an additional ICT layer to enable a fully autonomous trading system. The conducted economic simulation is also showing a net positive present value and an acceptable internal return rate, which means that the whole scenario is economically feasible.

\section{References}

Brown, M., Woodhouse, S., \& Sioshansi, F. (2019). Digitalization of energy. In Consumer, Prosumer, Prosumager: Elsevier Inc.

Long, C., Wu, J., Zhang C., Thomas L., Cheng M., \& Jenkins N. (2020). Peer-to-peer energy trading in a community microgrid. IEEE.

Chen, K., Lin, J., \& Song, Y. (2019). Trading strategy optimization for a prosumer in continuous double auction- based peer-to-peer market: A prediction-integration model. Applied Energy, 242, 11211133.

Cooper P. I., The absorption of solar radiation in solar stills, Solar Energy, 12:3-10, 1969.

Hottel, H. C. (1976). A simple model for estimating the transmittance of direct solar radiation through clear atmospheres, Solar Energy.

IESR. (2019). Indonesia clean energy outlook: Tracking progress and review of clean energy development in Indonesia.

IRENA. (2020). Global renewables outlook: energy transformation 2050.

J. A. Duffie \& W. A. Beckman, Solar engineering of thermal processes, John Wiley \& Sons, New York, 1980.

Leong, H., Gu, C., Li, F., \& Gu, C. (2019). Science direct auction mechanism for P2P local energy trading considering auction mechanism for P2P local energy trading considering physical constraints physical constraints the feasibility of using the heat demand-outdoor Chou Hon for temperature function a long-term district. Energy Procedia, 158, 6613-6618.

Liu, B. Y. H., \& Jordan, R. C. (1960). The interrelationship and characteristic distribution of direct, diffuse and total solar radiation, solar energi.

Lopes, F. (2012). Negotiating bilateral contracts in a multi-agent electricity market: A case study. 326330.

Mengelkamp, E., Gärttner, J., Rock, K., Kessler, S., \& Orsini, L. (2017). Designing microgrid energy markets A case study : The Brooklyn Microgrid. Applied Energy.

Presidential Regulation. (2017). Rencana umum energi nasional. Jakarta.

Spencer, J. W. (1971). Fourier series representation of the position of the sun, Search.

Morstyn, T., Teytelboym, A., \& McCulloch, M. D. (2019). Bilateral contract networks for peer-to-peer energy trading. IEEE Transactions on Smart Grid, 10(2)

Tushar, W., Chai, B., Yuen, C., Member, S., Huang, S., Smith, D. B., Poor, H. V., \& Yang, Z. (2016). Energy storage sharing in smart grid: A modified auction-based approach. 1-14.

Wang, C., Wu, J., Ekanayake, J., \& Jenkins, N. (2017). Smart electricity distribution networks.

Zhang, C., Wu, J., Cheng, M., Zhou, Y., \& Long, C. (2016). A bidding system for peer-to-peer energy trading in a grid-connected microgrid. Energy Procedia, 103 (April), 147-152. 